\title{
Development and physicochemical characterization of solid dispersions containing praziquantel for the treatment of schistosomiasis
}

\author{
P. R. Dametto ${ }^{1}$ - A. C. Dametto ${ }^{2}$ - L. Polese ${ }^{3}$ C. A. Ribeiro ${ }^{2}$ - M. Chorilli ${ }^{4}$. \\ Osvaldo de Freitas ${ }^{1}$
}

Received: 4 April 2016/Accepted: 1 August 2016/Published online: 16 August 2016

(C) Akadémiai Kiadó, Budapest, Hungary 2016

\begin{abstract}
Praziquantel (PZQ) is an anthelminthic agent active against parasitic flatworms of the Schistosoma type and the most important drug for the treatment and morbidity control of schistosomiasis. In this study, a highperformance liquid chromatography method was employed for quantification of PZQ in the physical mix (PM) and solid dispersion (SD) prepared by Fusion Method utilizing the carriers Gelucire ${ }^{\circledR} 50 / 13$ and mannitol in ratio $3: 1 ; 1: 1$; 1:3 PZQ/carrier. Furthermore, PM and SD were characterized by Thermogravimetry-Differential Thermal Analysis, Differential Scanning Calorimetry, Infrared Spectroscopy, X-Ray Diffraction, and Scanning Electron Microscopy. Solubility assay was made to evaluate the solubility of PZQ in purified water, in $0.1 \mathrm{~mol} \mathrm{~L}^{-1} \mathrm{HCl}$ solution and $0.2 \mathrm{~mol} \mathrm{~L}^{-1}$ buffered phosphate solution. PZQ dissolution test was carried out in $0.1 \mathrm{~mol} \mathrm{~L}^{-1} \mathrm{HCl}$ and $0.2 \mathrm{M}$ buffered phosphate $(\mathrm{pH}$ 6.8). The interaction between PZQ and carriers in PMs and SDs was evidenced due to experimental enthalpy, which was different from expected enthalpy. However, this interaction did not affect the solubility of the drug. In PZQ dissolution test, the best result was for SD 1:1 PZQ/Gelucire, which presented higher dissolution rate and release extension than PM and
\end{abstract}

P. R. Dametto

pdametto@gmail.com

1 Faculdade de Ciências Farmacêuticas, USP, Ribeirão Prêto, SP CEP 14040-903, Brazil

2 Instituto de Química, UNESP, Araraquara, SP CEP 14801-970, Brazil

3 Instituto de Biociências, UNESP, Rio Claro, SP CEP 13506-900, Brazil

4 Faculdade de Ciências Farmacêuticas, UNESP, Araraquara, SP CEP 14801-902, Brazil
PZQ. Thus, SD may be a strategy to enhance the solubility and dissolution, a crucial step in the development of a pharmaceutical dosage form containing PZQ for possible application in the treatment of schistosomiasis.

Keywords Praziquantel · HPLC-UV · Physical mix · Solid dispersion

\section{Introduction}

Praziquantel (PZQ) 2-cyclohexylcarbonyl[1-3,6,7,11b]hexahydro-4H-pyrazino[2,1-a]isoquinolin-4-one (Fig. 1), a synthetic heterocyclic anthelminthic agent, is broadly effective against flatworms, including trematodes, human and veterinary cestodes, and displays cysticidal effects. This drug has been used for the treatment of schistosomiasis (bilharziasis) caused by all Schistosoma species pathogenic to humans because it is effective against all stages of Schistosoma infection including the acute phase and the chronic phase, which may associate with hepatosplenic involvement. In additional, it also has been used for the treatment of clonorchiasis caused by Clonorchis sinensis (Chinese liver fluke) and opisthorchiasis caused by Opisthorchis viverrini (liver fluke) [1]. For this reason, PZQ has become the drug of choice for the treatment and morbidity control of schistosomiasis, a disease that affects about 200 million people worldwide, leading to the loss of 1.53 million disability-adjusted life years [2].

Praziquantel is classified as a class II drug, i.e., has low solubility and high permeability $[3,4]$. The low solubility $\left(0.4 \mathrm{mg} \mathrm{mL}^{-1}\right)$ is the limiting factor in the bioavailability this drug [5]. Several techniques can be used to improve the dissolution and bioavailability of poorly water soluble, such as size reduction, the use of surfactants, salt 
<smiles>O=C(C1CCCCC1)N1CC(=O)N2CCc3ccccc3[C@H]2C1</smiles>

Fig. 1 The structure of praziquantel

formation, $\mathrm{pH}$ adjustments, prodrugs, complexation with cyclodextrins, self-emulsifying formulations, emulsions [6] and liposomes [6, 7].

A possible way to increase the solubility of PZQ in aqueous solution is to alter the physical properties of the drug by preparing a solid dispersion (SD) [8]. The solid-state form (i.e., crystalline polymorphs, solvates, amorphous solids) of the drug has a significant impact on physical properties such as solubility, dissolution rate, activity and bioavailability [9]. The SD technique produces a significant increase in surface area and surface wettability as well as solid-state modification from crystalline to amorphous form. However, the SD characteristics can be influenced by several factors such as preparation method, carrier type, and drug/carrier ratio and $\mathrm{pH}$ modifiers [10,11]. Thus, it is interesting to use a simple and economical method for preparing solid dispersions. On the other hand, the fusion method which has all advantages already cited consists in the incorporation of the drug into a carrier by heating to temperatures slightly above the melting point of the drug. It applies to drugs and carriers, thermostable and are miscible liquid [12].

Data from literature have shown that SD was usually prepared using carriers which are water-soluble substances such as mannitol [13, 14], urea [15], polyvinylpyrrolidone (PVP) $[14,16]$, poly(ethylene glycol) (PEG) [14, 16-18], and polyoxylglyceride [19-21] by two major methods: fusion and solvent evaporation $[10,22]$. The analytical methods to quantify the PZQ in SD described are spectrophotometry $[11,23]$ and HPLC [24-26]. The aim of this study was to

Table 1 Parameters of validation obtained by analytical curves of the praziquantel

\begin{tabular}{ll}
\hline Parameters & Values \\
\hline Sensibility/mAU mg kg & -1 \\
Working range/mg kg & 683134.9 \\
Accuracy & $0.48-4.97$ \\
& $5.4 \geq 106 \pm 4$ \\
& $6.8 \geq 104 \pm 11$ \\
$\mathrm{LQ} / \mathrm{mg} \mathrm{kg}^{-1}$ & $7.8 \geq 110 \pm 5$ \\
$\mathrm{LD} / \mathrm{mg} \mathrm{kg}^{-1}$ & 0.27 \\
Linearity & 0.080 \\
Correlation coefficient & $y=683134.9 x+5157.8$ \\
\hline
\end{tabular}

(a)

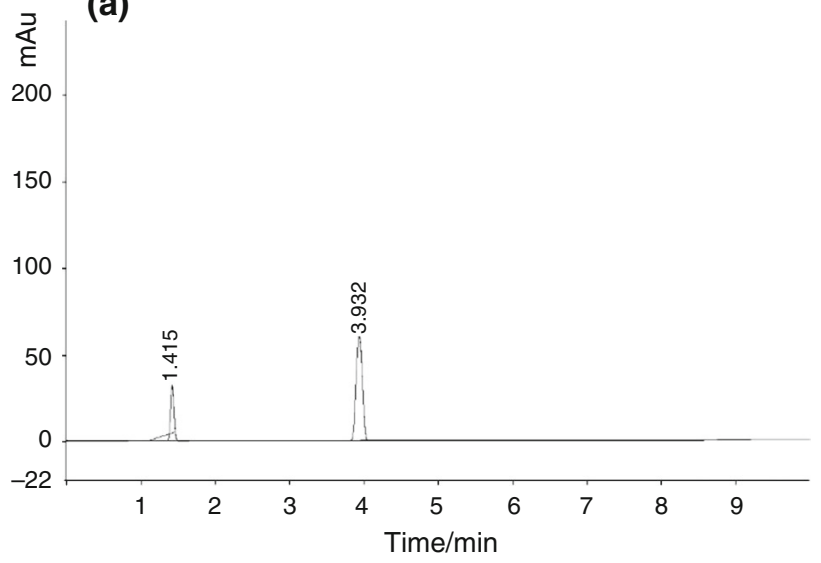

(b)

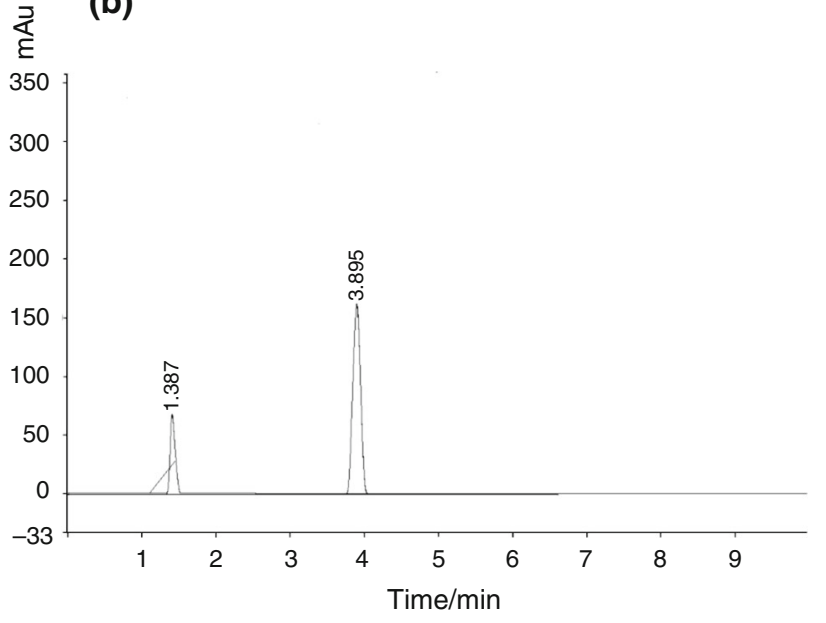

Fig. 2 HPLC chromatograms at $210 \mathrm{~nm}$ : a standard of praziquantel $(\mathrm{SPZQ}, R T=3.932$ ) and $\mathbf{b}$ solid dispersion 1:1 PZQ/Gelucire (PZQ, $R T=3.895)$

prepare different solid dispersions and evaluate the PZQ solubility compared with physical mixtures by HPLC method.

\section{Experimental}

\section{Materials}

Standard Praziquantel (SPZQ, $99 \%$ ) was purchased from Sigma-Aldrich (Sigma-Aldrich Chemical Co., St. Louis, MO, USA), and Praziquantel (PZQ) was donated by Brazilian Industry (Ourofino, Brazil), Mannitol (Pharma Nostra, Brazil), polyoxylglyceride: Gelucire ${ }^{\circledR}$ 50/13 (Gattefossé, France). Acetonitrile used for HPLC analysis was of ACS reagent grade purchased from JT Baker ${ }^{\circledR}$ (Center Valley, PA, USA). Sodium phosphate monobasic and sodium phosphate tribasic were ACS reagent grade obtained from Synth (Diadema, SP, Brazil), hydrochloric acid 36.5-38 \% w/w (JT Baker ${ }^{\circledR}$, Center Valley, PA, USA) and ultrapure water (Millipore system, Billerica, USA). 

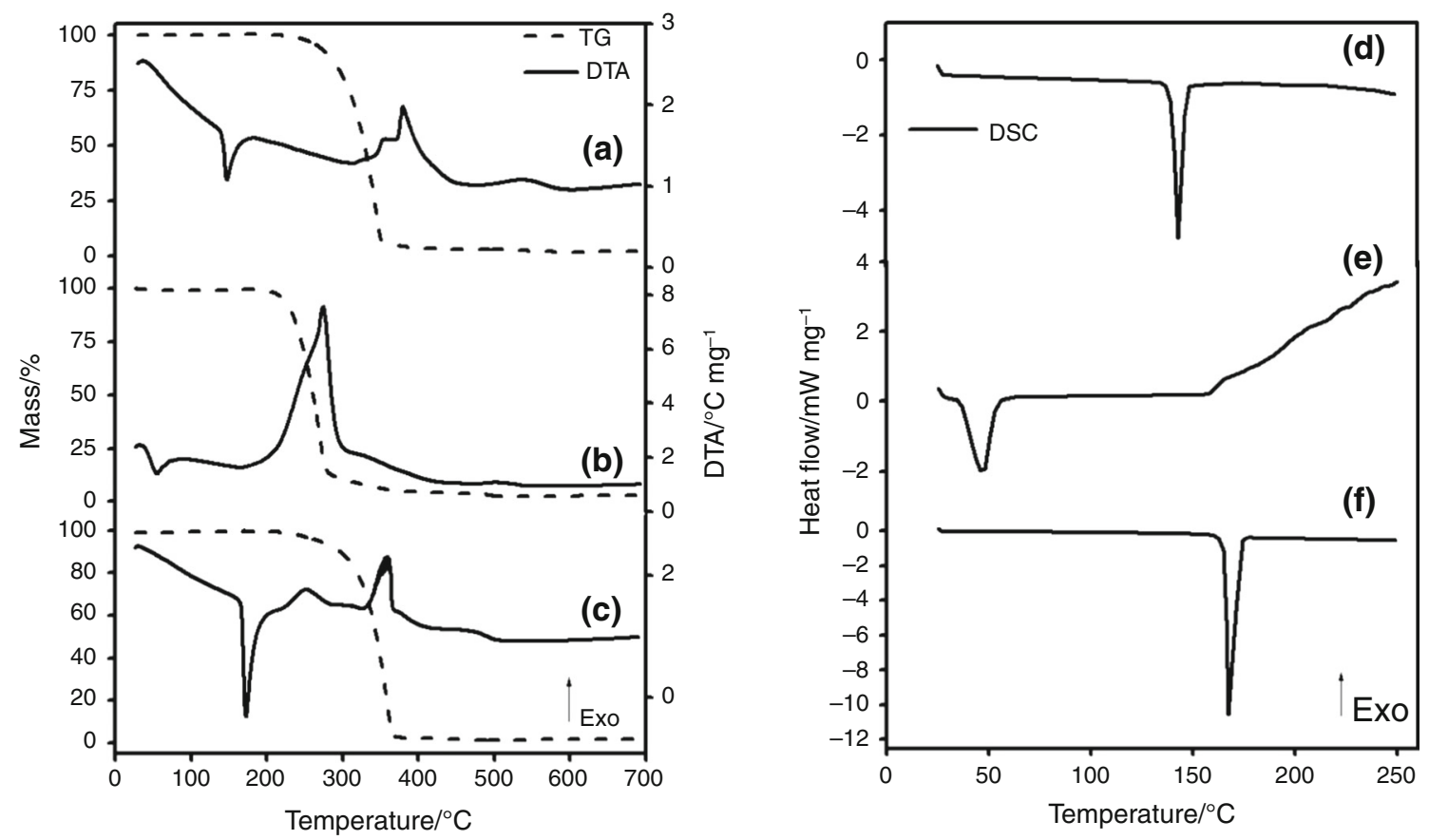

Fig. 3 TG-DTA curves: $a$ PZQ, $b$ Gelucire, $c$ mannitol and DSC curves, $d$ PZQ, $e$ Gelucire, $f$ mannitol
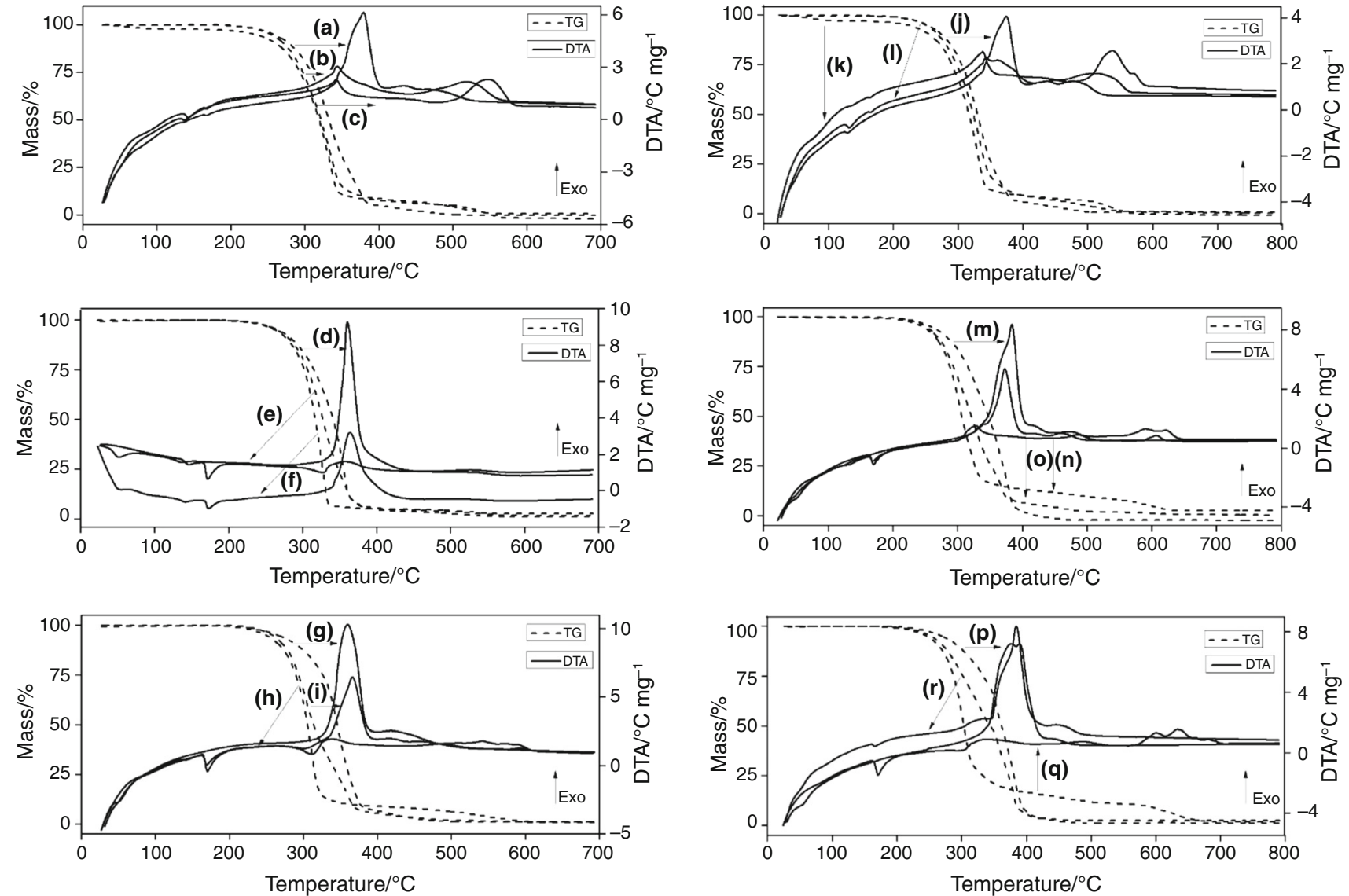

Fig. 4 TG-DTA curves: $a$ PM 3:1 PZQ/G, $b$ PM 3:1 PZQ/M, $c$ PM 3:1 PZQ/G + M, $d$ PM 1:1 PZQ/G, $e$ PM 1:1 PZQ/M, $f$ PM 1:1 PZQ/ $\mathrm{G}+\mathrm{M}, g$ PM 1:3 PZQ/G, $h$ PM 1:3 PZQ/M, $i$ PM 1:3 PZQ/G + M,

$j$ SD 3:1 PZQ/G, $k$ SD 3:1 PZQ/M, $l$ SD 3:1 PZQ/G + M, $m$ SD 1:1 $\mathrm{PZQ} / \mathrm{G}, n$ SD 1:1 PZQ/M, $o$ SD 1:1 PZQ/G + M, $p$ SD 1:3 PZQ/G, $q$ SD $1: 3 \mathrm{PZQ} / \mathrm{M}, r$ SD $1: 3 \mathrm{PZQ} / \mathrm{G}+\mathrm{M}$ 

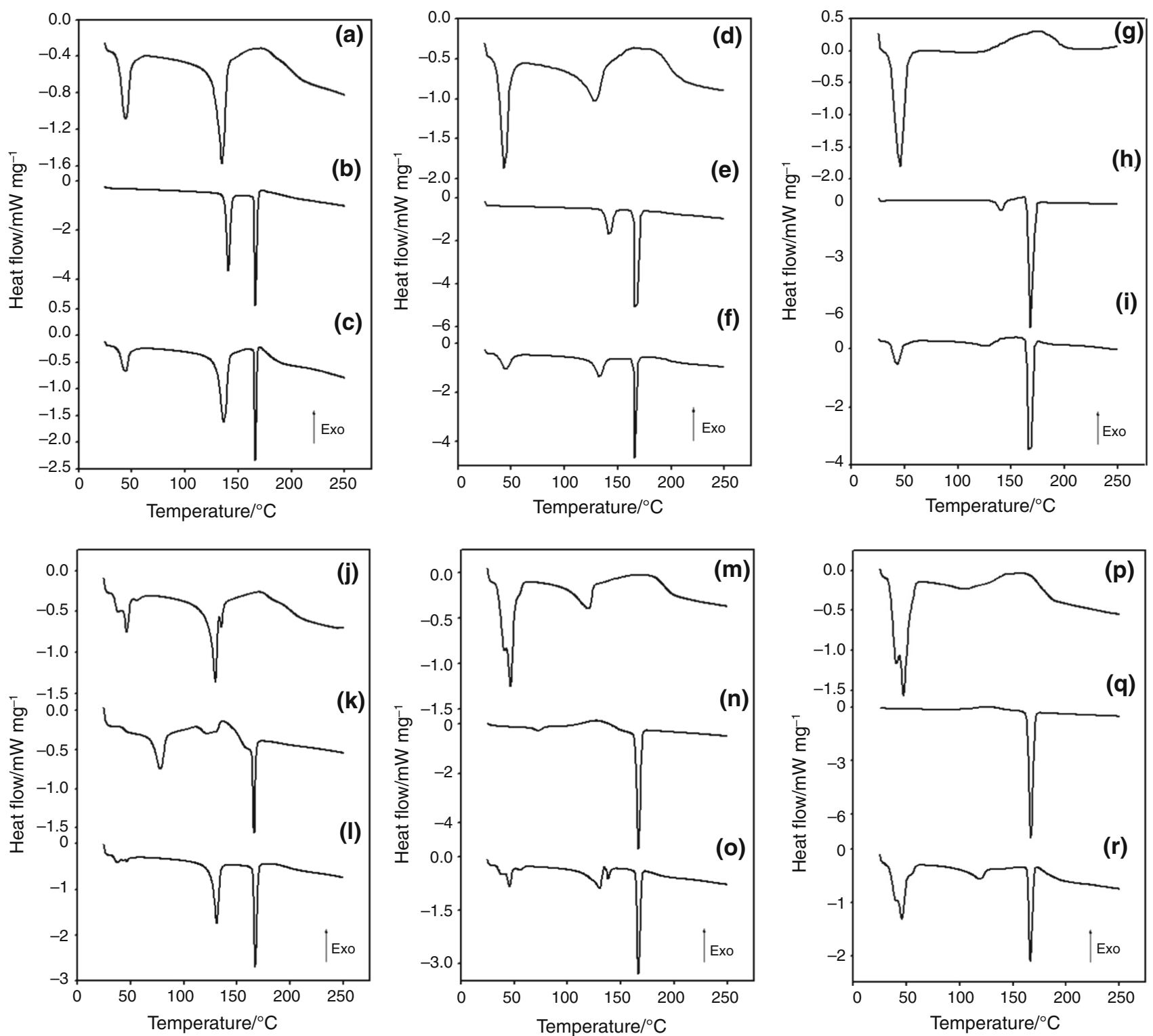

Fig. 5 DSC curves: $a$ PM 3:1 PZQ/G, $b$ PM 3:1 PZQ/M, $c$ PM 3:1 $\mathrm{PZQ} / \mathrm{G}+\mathrm{M}, d$ PM 1:1 PZQ/G, $e$ PM 1:1 PZQ/M, $f$ PM 1:1 PZQ/ $\mathrm{G}+\mathrm{M}, g$ PM 1:3 PZQ/G, $h$ PM 1:3 PZQ/M, $i$ PM 1:3 PZQ/G + M, $j \mathrm{SD} 3: 1 \mathrm{PZQ} / \mathrm{G}, k$ SD 3:1 PZQ/M, $l$ SD 3:1 PZQ/G + M, $m$ SD 1:1 $\mathrm{PZQ} / \mathrm{G}, n$ SD 1:1 PZQ/M, $o$ SD 1:1 PZQ/G + M, $p$ SD 1:3 PZQ/G, $q \mathrm{SD} 1: 3 \mathrm{PZQ} / \mathrm{M}, r$ SD $1: 3 \mathrm{PZQ} / \mathrm{G}+\mathrm{M}$

\section{Analytical conditions for HPLC analyses and quantification}

Quantification of the praziquantel was carried out using a Varian liquid chromatography system equipped with two pumps (Pro Star-210), Rheodyne manual injector (model 7161), and UV/Vis detector (Varian, Palo Alto, CA, USA). All samples were filtered through a membrane $(0.45 \mu \mathrm{m})$, and $20 \mu \mathrm{L}$ were injected into HPLC using a Phenomenex RP-18 pre-column $(4 \mathrm{~mm} \times 30 \mathrm{~mm}$ i.d; $5 \mu \mathrm{m})$ and a Phenomenex Luna RP-18 column $(250 \mathrm{~mm} \times 4.6 \mathrm{~mm}$ i.d, $5 \mu \mathrm{m})$. The analyses were performed using acetonitrile/ water $(60: 40, v / v)$ under isocratic elution at a flow rate of $1.5 \mathrm{~mL} \mathrm{~min}^{-1}$. The PZQ detected at $210 \mathrm{~nm}[24,27]$. The total running time was $10 \mathrm{~min}$.

The standard solutions were prepared based on American Pharmacopeia to afford five solutions at concentration $0.50,1.20,2.50,3.70,5.00 \mathrm{mg} \mathrm{kg}^{-1}$. Each solution was injected in triplicate [28].

\section{Sample preparation}

Physical mixtures (PM) of PZQ with Gelucire ${ }^{\circledR}$ 50/13 and mannitol were prepared by mechanical agitation. 
Table 2 DSC curves parameters

\begin{tabular}{|c|c|c|c|c|}
\hline Sample & $T_{\text {peak }} /{ }^{\circ} \mathrm{C}$ & $T_{\text {onset }} /{ }^{\circ} \mathrm{C}$ & $\Delta H_{\text {experimental }} / \mathrm{J} \mathrm{g}^{-1}$ & $\Delta H_{\text {expected }} / \mathrm{J} \mathrm{g}^{-1}$ \\
\hline PZQ & 142.9 & 140.2 & 98.4 & 98.4 \\
\hline Gelucire & 46.8 & 36.8 & 129.2 & 129.2 \\
\hline Mannitol & 167.5 & 164.9 & 286.7 & 286.7 \\
\hline PM 3:1 (PZQ/G) & 44.7 and 134.7 & 37.8 and 129.4 & 31.4 and 49.6 & 32.3 and 73.8 \\
\hline PM 3:1 (PZQ/M) & 165.90 and 140.67 & 137.5 and 164.7 & 60.2 and 73.0 & 73.8 and 71.7 \\
\hline $\mathrm{PM} 3: 1(\mathrm{PZQ} / \mathrm{G}+\mathrm{M})$ & $44.1 ; 136.5$ and 165.9 & $37.9 ; 130.4$ and 164.8 & $15.9 ; 53.2$ and 21.5 & $32.3 ; 73.8$ and 71.7 \\
\hline SD 3:1 (PZQ/G) & $37.8 ; 46.6 ; 129.9$ and 135.5 & $34.9 ; 43.9 ; 124.6$ and 133.6 & $6.46 ; 2.31 ; 29.0$ and 2.29 & 32.3 and 73.8 \\
\hline SD 3:1 (PZQ/M) & $78.2 ; 129.4$ and 166.3 & $70.9 ; 114.3$ and 164.1 & $20.0 ; 9.86$ and 16.43 & 73.8 and 71.7 \\
\hline SD 3:1 (PZQ/G + M) & $37.4 ; 46.4 ; 131.1$ and 167.0 & $34.0 ; 44.2 ; 126.5$ and 165.3 & $1.68 ; 1.14 ; 43.4$ and 40.5 & $32.3 ; 73.8$ and 71.7 \\
\hline PM 1:1 (PZQ/G) & 44.1 and 130.1 & 37.3 and $121 ., 7$ & 55.6 and 15.7 & 64.6 and 49.2 \\
\hline PM 1:1 (PZQ/M) & 142.3 and 166.7 & 136.9 and 164.9 & 45.1 and 131.9 & $49 ., 2$ and 143.4 \\
\hline PM 1:1 (PZQ/G + M) & $45.2 ; 133.2$ and 166.0 & $37.3 ; 127.8$ and 164.7 & $29.9 ; 31.9$ and 58.4 & $32.3 ; 49.2$ and 143.4 \\
\hline SD 1:1 (PZQ/G) & 46.5 and 119.9 & 39.7 and 103.3 & 70.6 and 18.6 & 64.6 and 49.2 \\
\hline SD 1:1 (PZQ/M) & 72.6 and 166.9 & 67.2 and 163.6 & 4.15 and 108.1 & 49.2 and 143.4 \\
\hline SD 1:1 (PZQ/G + M) & $45.8 ; 130.3 ; 138.0$ and 166.3 & $41.5 ; 121.3 ; 136.5$ and 164.4 & $26.7 ; 28.8 ; 5.70$ and 56.3 & $32.3 ; 49.2$ and 143.4 \\
\hline PM 1:3 (PZQ/G) & 45.9 and 122.3 & 36.9 and 112.3 & 101.4 and 0.91 & 96.9 and 24.6 \\
\hline PM 1:3 (PZQ/M) & 140.6 and 168.3 & 135.4 and 165.0 & 20.2 and 181.7 & 24.6 and 215.0 \\
\hline PM 1:3 (PZQ/G + M) & $43.2 ; 127.0$ and 167.5 & $36.8 ; 109.2$ and 164.6 & $37.0 ; 20.1$ and 37.0 & $96.9 ; 24.6$ and 215.0 \\
\hline SD 1:3 (PZQ/G) & $39.7 ; 47.4$ and 106.5 & $36.0 ; 44.3$ and 105.9 & $9.57 ; 19.2$ and 5.63 & 96.9 and 24.6 \\
\hline SD 1:3 (PZQ/M) & 145 and 166.9 & 129.7 and 163.6 & 0.71 and 180.9 & 24.6 and 215.0 \\
\hline SD 1:3 (PZQ/G + M) & $39.2 ; 46.055 .1 ; 120.2$ and 166.3 & $32.9 ; 42.6 ; 51.7,113.0$ and 164.9 & $3.41 ; 14.3 ; 0.86 ; 5.31$ and 39.1 & $96.9 ; 24.6$ and 215.0 \\
\hline
\end{tabular}

The relative proportions of carrier/PZQ were 1:1, 1:3 and $3: 1$.

The solid dispersions were prepared by Fusion Method following the protocol: PZQ, mannitol, and Gelucire were heated separately to their melting point. The compound which has a minor melting point was added in the others under constant agitation until the mixture solidified naturally $[29,30]$. The relative proportions of carrier/PZQ were the same used for the PM.

\section{Thermal behavior and characterization}

Thermogravimetry-Differential Thermal Analysis (TGDTA) and Differential Scanning Calorimetry (DSC) were carried out using SDT 2960 (TA Instruments, New Castle, DE, USA) and DSC1 Stare System (Mettler Toledo, Barueri, SP, Brazil), respectively. The used method was previously described by Dametto et al. [31] with minor modifications. Briefly, TG-DTA curves were obtained from samples of 7.0 to $7.2 \mathrm{mg}$ in open alumina crucibles heated at $10{ }^{\circ} \mathrm{C} \mathrm{min}-1$ under an air atmosphere flowing at $100 \mathrm{~mL} \mathrm{~min}^{-1}$. DSC curves were obtained from samples of 5.0 to $5.1 \mathrm{mg}$ in open aluminum crucibles heated at $10^{\circ} \mathrm{C} \mathrm{min}^{-1}$ under an air atmosphere flowing at $50 \mathrm{~mL} \mathrm{~min}{ }^{-1}$.

Infrared spectra were obtained by Nicolet model Impact 400 FT-IR Instrument (Jasco Analytical Instruments, Easton, MD, USA), in the range from 4000 to $400 \mathrm{~cm}^{-1}$. The solid samples prepared into $\mathrm{KBr}$ pellets.
X-ray powder patterns were obtained using SIEMENS ${ }^{\circledR}$ D-5000 (Siemens AG, Munich, Germany) X-ray diffractometer with $\mathrm{CuK} \alpha$ radiation $(\lambda=1.541 \AA)$, current and voltage of $20 \mathrm{kV}$, and $20 \mathrm{~mA}$, respectively. The scanning $\mathrm{X}$-ray angle ranged from $2^{\circ}$ to $80^{\circ}$ in $2 \theta$ steps of $0.02^{\circ}$ and a counting time of $2 \mathrm{~s} / \mathrm{step}$. Samples were prepared following USP method 941 recommendation [32].

The photomicrographs were obtained by using TOPCON SM-300 Scanning Electron Microscopy (SEM) with an acceleration voltage of $20 \mathrm{kV}$. Before analysis, the sample was coated with gold $\pm 20 \mathrm{~nm}$ of thickness.

\section{Solubility assay}

The solubility assay was performed dissolving PZQ (12.0 mg), PMs (24.0 mg), and SDs $(24.0 \mathrm{mg})$ in $10 \mathrm{~mL}$ of distilled water, $10 \mathrm{~mL} \mathrm{HCl}$ solution $\left(0.1 \mathrm{~mol} \mathrm{~L}^{-1} \mathrm{pH} 1\right)$, and $10 \mathrm{~mL}$ buffered phosphate solution $\left(0.2 \mathrm{~mol} \mathrm{~L}^{-1} \mathrm{pH}\right.$ $6.8)$ at $23 \pm 0.5{ }^{\circ} \mathrm{C}$. Such solutions were stirred for $24 \mathrm{~h}$, filtered using a membrane $(0.45 \mu \mathrm{m})$ and analyzed by HPLC. Each sample was injected in triplicate [28].

\section{In vitro drug dissolution}

The drug dissolution test was carried out using dispersion apparatus 2 at $37 \pm 0.5{ }^{\circ} \mathrm{C}$ and $50 \mathrm{rpm}$ in $\mathrm{HCl}\left(0.1 \mathrm{~mol} \mathrm{~L}^{-1}\right)$, as described in USP-30. After $2 \mathrm{~h}$ of operation in acid solution was added sodium phosphate tribasic buffer 

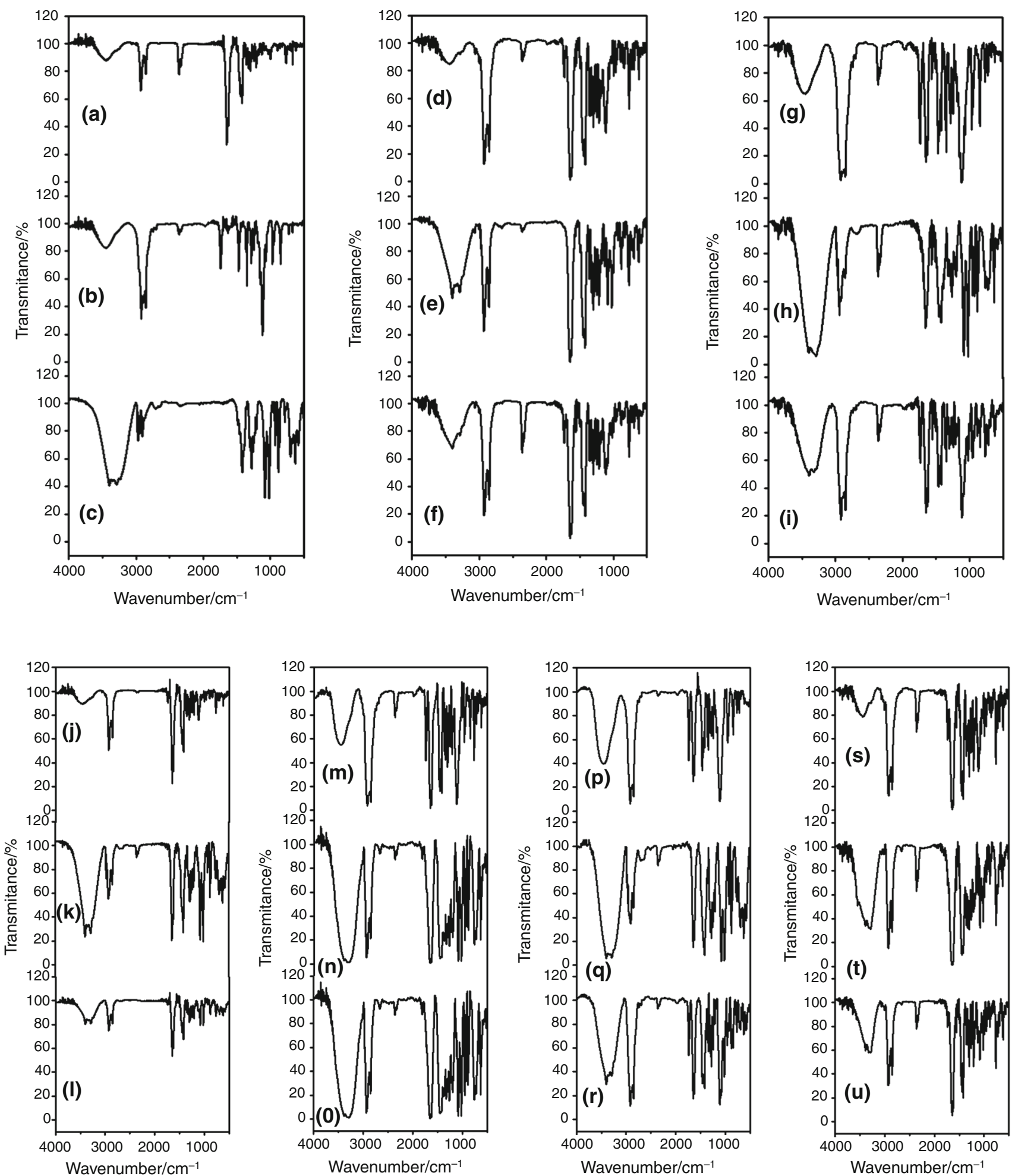

Fig. 6 Infrared Spectrum: $a$ PZQ, $b$ mannitol, $c$ Gelucire, $d$ PM 3:1 $\mathrm{PZQ} / \mathrm{G}, e$ PM 3:1 PZQ/M, $f$ PM 3:1 PZQ/G + M, $g$ SD 3:1 PZQ/G, $h$ SD 3:1 PZQ/M, $i$ SD 3:1 PZQ/G + M, $j$ PM 1:1 PZQ/G, $k$ 1:1 PZQ/

$\mathrm{M}, l \mathrm{PM} 1: 1 \mathrm{PZQ} / \mathrm{G}+\mathrm{M}, m$ SD $1: 1 \mathrm{PZQ} / \mathrm{G}, n$ SD $1: 1 \mathrm{PZQ} / \mathrm{M}, o$ SD $1: 1 \mathrm{PZQ} / \mathrm{G}+\mathrm{M}, p$ PM $1: 3 \mathrm{PZQ} / \mathrm{G}, q 1: 3 \mathrm{PZQ} / \mathrm{M}, r$ PM $1: 3 \mathrm{PZQ} /$ $\mathrm{G}+\mathrm{M}, s$ SD 1:3 PZQ/G, $t$ SD 1:3 PZQ/M, $u$ SD 1:3 PZQ/G + M 


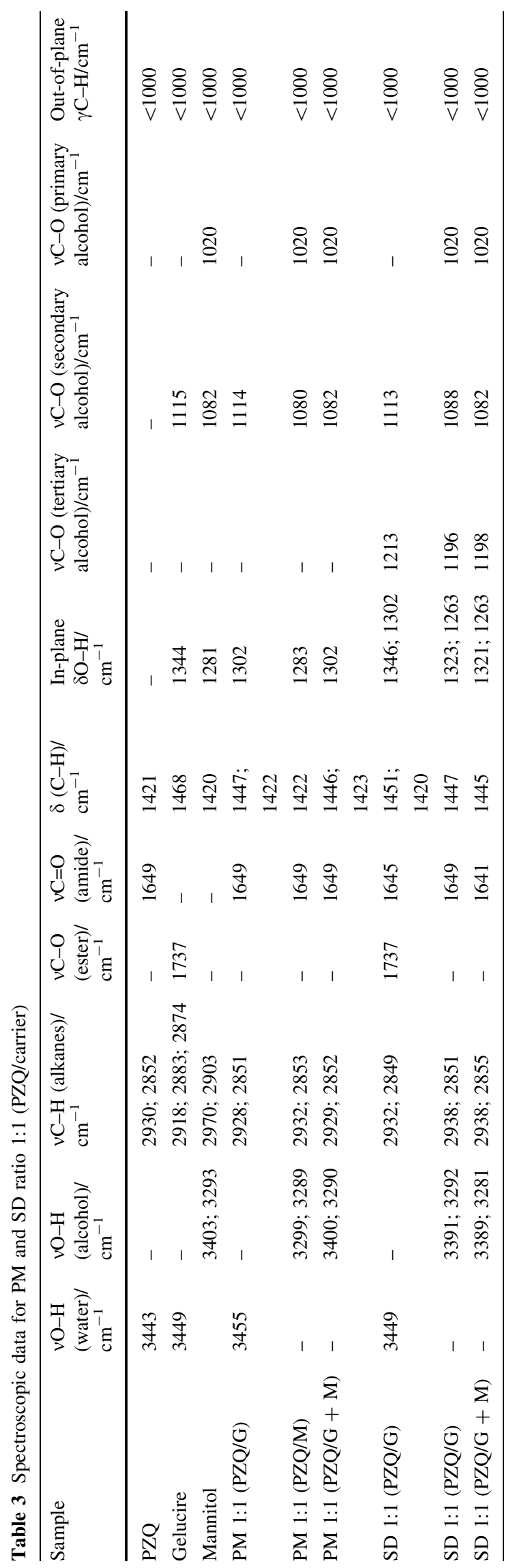

$\left(0.2 \mathrm{~mol} \mathrm{~L}^{-1}\right)$, and the final solution kept in constant agitation for $4 \mathrm{~h}$ [33]. The system was maintained under sink conditions. An aliquot of $5.0 \mathrm{~mL}$ of the solution was taken at $5,10,20,50,90,120,180,240,300$ and $360 \mathrm{~min}$. This aliquot was immediately filtered through membranes $(0.45 \mu \mathrm{m})$ and frozen. The temperature was kept at $37{ }^{\circ} \mathrm{C}$, and the volume dissolution medium was maintained constant by the addition of $5.0 \mathrm{~mL} 0.1 \mathrm{~mol} \mathrm{~L}^{-1} \mathrm{HCl}$ or buffer. The concentration of PZQ at each time point was determined by HPLC.

\section{Results and discussion}

The experimental conditions of the HPLC analysis were the same used by Oltean [24] for determination of PZQ in tablet dosages forms. The parameters determined were selectivity, linearity, limit of detection, limit of quantification, accuracy and precision, according to International Conference on Harmonization [28]. The obtained results are shown in Table 1.

\section{Selectivity}

The selectivity was evaluated at $210 \mathrm{~nm}$ by comparing of retention time $\left(t_{\mathrm{R}}\right)$ obtained for standard and sample of solid dispersions. The retention time (RT) of PZQ standard and PZQ in solid dispersions was $3.9 \mathrm{~min}$ (Fig. 2). Therefore, this method is selective because it can detect PZQ in the presence of carriers, mannitol $(\lambda=200 \mathrm{~nm})$ and Gelucire $(\lambda=205 \mathrm{~nm})$ which show maximum wavelength near to $210 \mathrm{~nm}$.

\section{Working range and linearity}

The linearity was investigated at $210 \mathrm{~nm}$. The experimental data of the curves submitted to statistical analyses for rejection of anomalous values. The linearity showed values between 0.48 and $4.97 \mathrm{mg} \mathrm{kg}^{-1}$, and the correlation coefficient $\left(r^{2}\right)$ was 0.9999 . Each standard solution injected three times, and the peak area was plotted versus concentration of obtained the calibration curve with five data points $\left(0.50, \quad 1.20, \quad 2.50, \quad 3.70, \quad 5.00 \mathrm{mg} \mathrm{kg}^{-1}\right)$, $y=683134.9 x+5157.8$. The limit of quantification (LOQ) and limit of detection (LOD) calculated according to International Conference on Harmonization [28] and presented values of 0.27 and $0.080 \mathrm{mg} \mathrm{kg}^{-1}$, respectively.

\section{Accuracy and precision}

The accuracy was performed by recovering studies at three different levels, 80, 100, and $120 \%$ containing 40, 50, and $60 \mathrm{mg}$, respectively, of the standard in commercial samples 

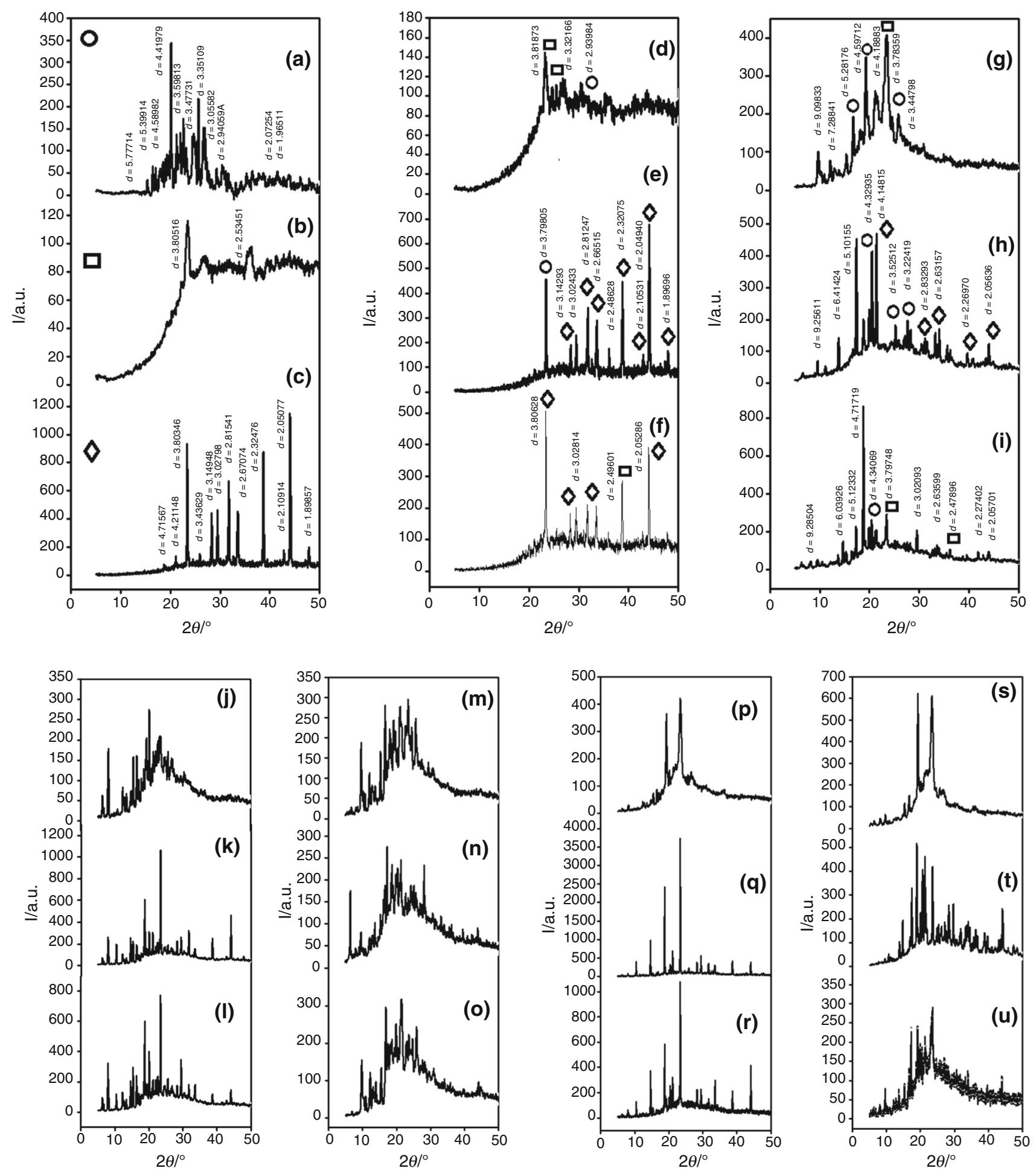

Fig. 7 XRD patterns: $a$ PZQ, $b$ mannitol, $c$ Gelucire, $d$ PM 1:1 PZQ/ G, $e$ PM 1:1 PZQ/M, $f$ PM 1:1 PZQ/G + M, $g$ SD $1: 1 \mathrm{PZQ} / \mathrm{G}, h$ SD 1:1 PZQ/M, $i$ SD 1:1 PZQ/G + M, $j$ PM 3:1 PZQ/G, $k$ 3:1 PZQ/M,

of PZQ. The recovery of the PZQ ranged from 104 to $110 \%$ with RSD lower than $11 \%$ (Table 1).

Standard solution at $2.5 \mathrm{mg} \mathrm{kg}^{-1}$ was injected six times in HPLC to evaluate the instrumental precision

$l \mathrm{PM} 3: 1 \mathrm{PZQ} / \mathrm{G}+\mathrm{M}, m$ SD $3: 1 \mathrm{PZQ} / \mathrm{G}, n$ SD $3: 1 \mathrm{PZQ} / \mathrm{M}, o$ SD $3: 1$ $\mathrm{PZQ} / \mathrm{G}+\mathrm{M}, p$ PM 1:3 PZQ/G, $q$ 1:3 PZQ/M, $r$ PM 1:3 PZQ/G + M, $s$ SD 1:3 PZQ/G, $t$ SD 1:3 PZQ/M, $u$ SD 1:3 PZQ/G + M

about retention time and peak. The RSD values obtained were 0.2 and $0.5 \%$ of retention time and peak area, respectively, and indicated a good instrumental precision. 


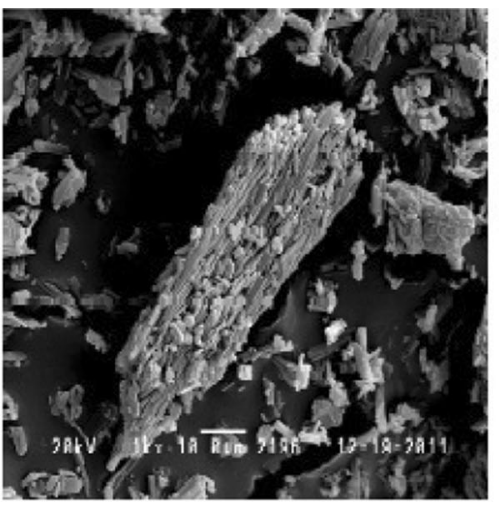

(a)

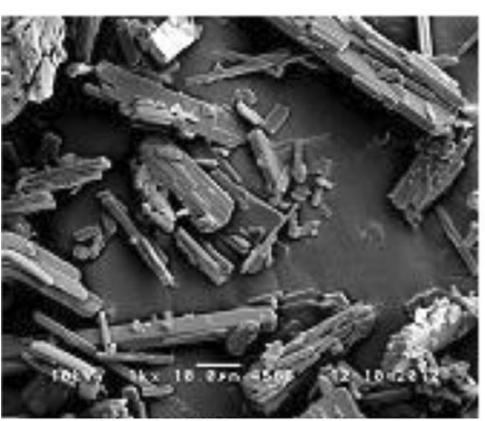

(d)

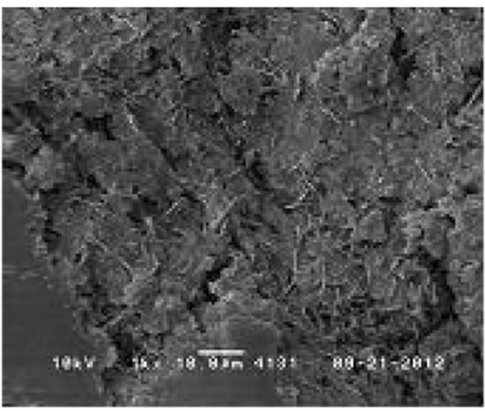

(g)

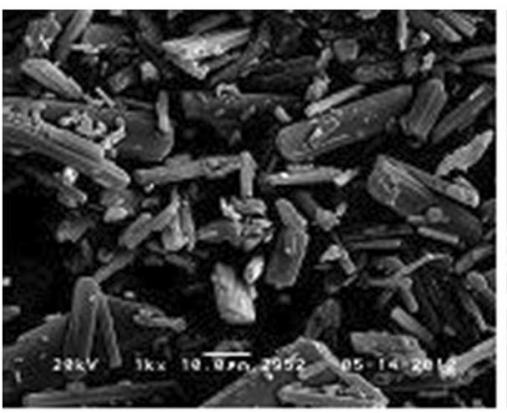

(j)

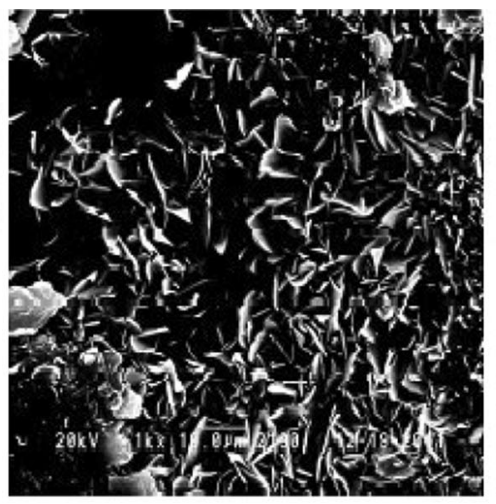

(b)

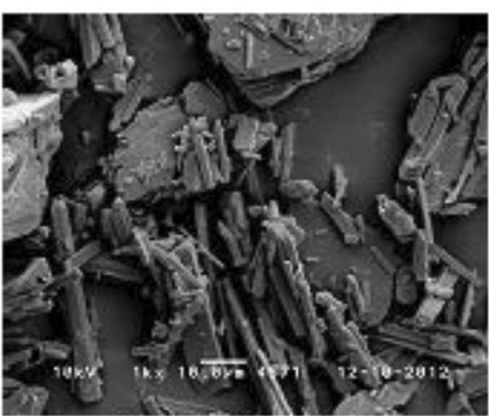

(e)

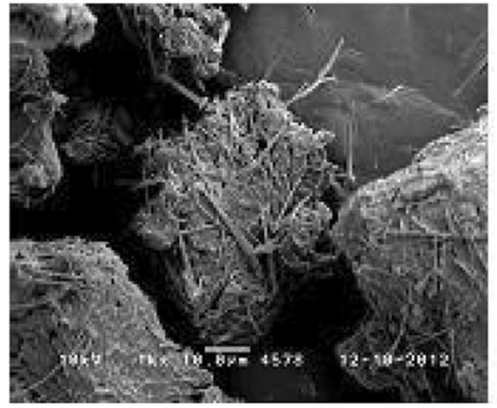

(h)

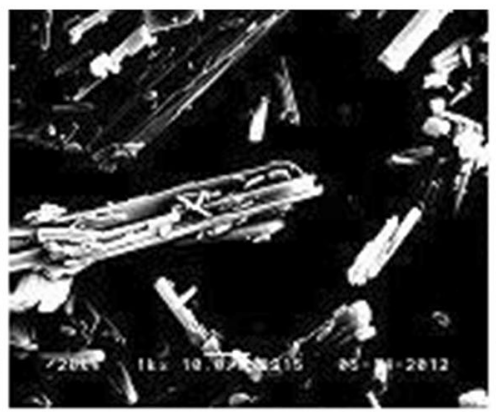

(k)

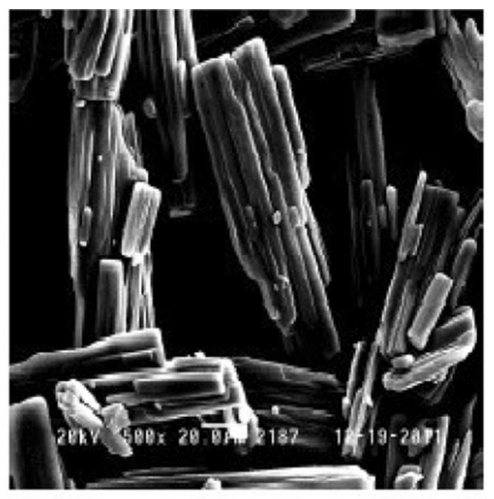

(c)

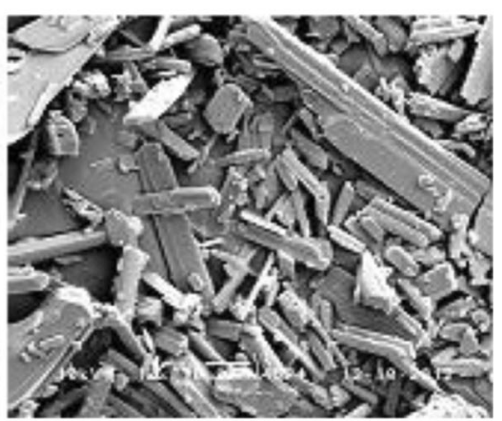

(f)

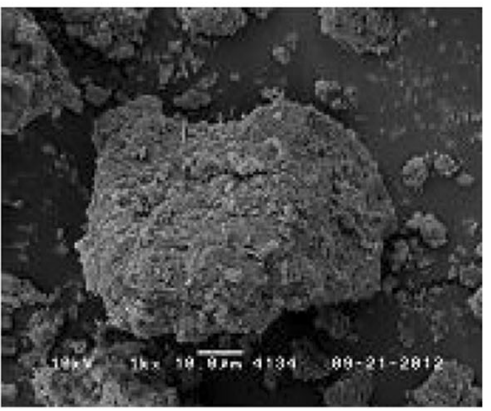

(i)

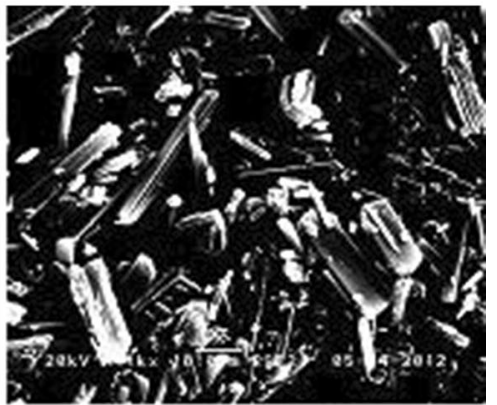

(I)

Fig. 8 MEV: a PZQ, b mannitol, c Gelucire, d PM 3:1 PZQ/G, e PM 3:1 PZQ/M, f PM 3:1 PZQ/G + M, g SD 3:1 PZQ/G, h SD 3:1 PZQ/ $\mathrm{M}$, i SD 3:1 PZQ/G + M, j PM 1:1 PZQ/G, k 1:1 PZQ/M, I PM 1:1

$\mathrm{PZQ} / \mathrm{G}+\mathrm{M}$, m SD 1:1 PZQ/G, n SD 1:1 PZQ/M, o SD 1:1 PZQ/ $\mathrm{G}+\mathrm{M}, \mathbf{p}$ PM 1:3 PZQ/G, q 1:3 PZQ/M, r PM 1:3 PZQ/G + M, s SD 1:3 PZQ/G, t SD 1:3 PZQ/M, u SD 1:3 PZQ/G + M 


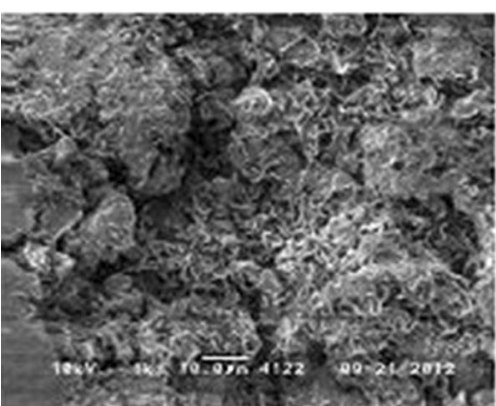

(m)

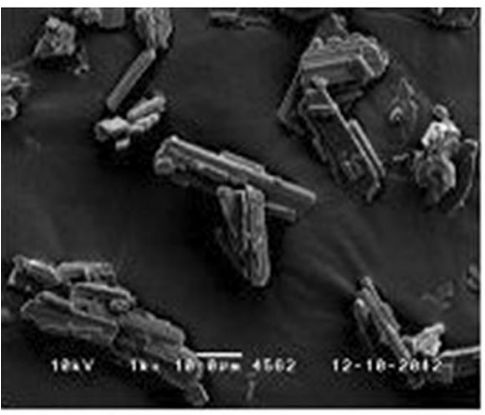

(p)

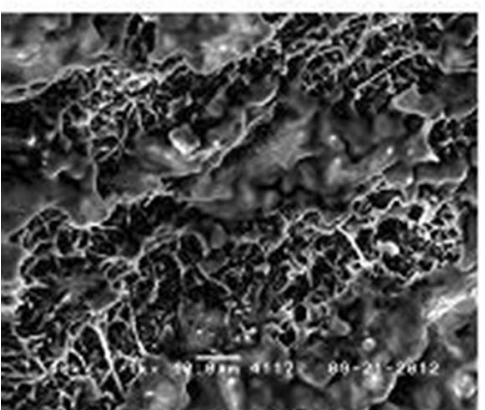

(s)

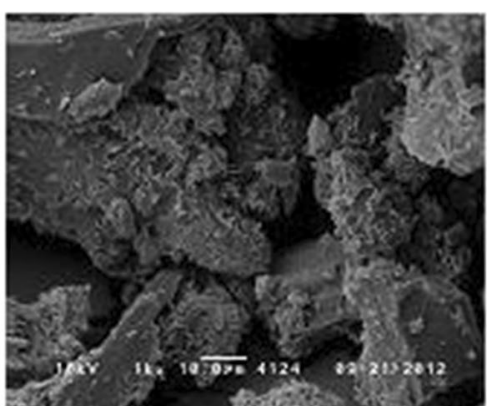

(n)

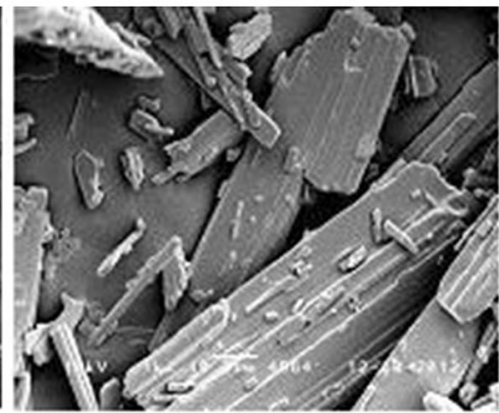

(q)

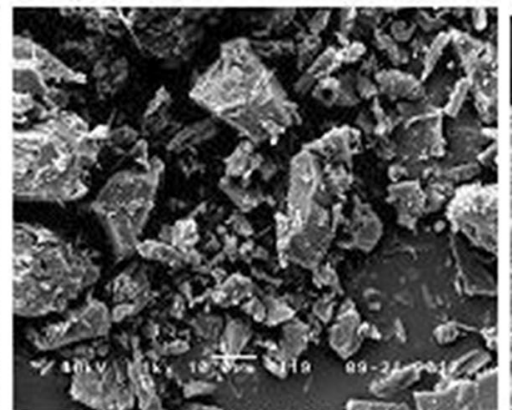

(t)

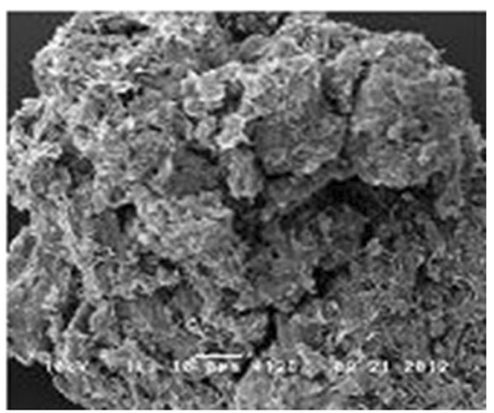

(o)

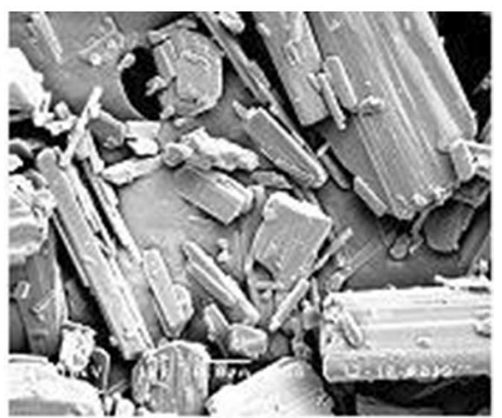

(r)

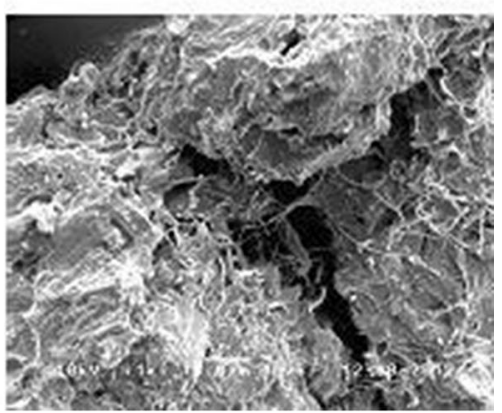

(u)

Fig. 8 continued

\section{Thermal behavior and characterization}

\section{Thermogravimetry-differential thermal analysis $(T G-$ DTA)}

TG curves of PZQ and mannitol showed only one step of thermal decomposition, whereas TG curve of Gelucire showed two steps of thermal decomposition. DTA curves showed endothermic peaks at 142,55 and $174{ }^{\circ} \mathrm{C}$, which were attributed to melting of PZQ, Gelucire, and mannitol, respectively (Fig. 3a-c).

The thermal stability and decomposition profile for PZQ, Gelucire, mannitol, PMs, and SDs were similar. The first step of decomposition for all samples was observed approximately at $200{ }^{\circ} \mathrm{C}$ (Fig. 4a-q). However, some melting peaks of PZQ, Gelucire, and mannitol were not observed in DTA curves (Fig. 4a-q). The exothermic peaks observed in DTA curves were attributed to oxidation of the organic matter that occurs after thermal decomposition of compounds (Fig. 4a-q). On the other hand, DSC curves showed all melting peaks (Fig. 5). This difference might be due to the low sensibility of DTA technique about the DSC technique.

\section{Differential Scanning Calorimetry (DSC)}

DSC curve of PZQ (Fig. 3d) showed an intense endothermic peak at $142.9{ }^{\circ} \mathrm{C}$, assigned to its melting point [34]. Endothermic peaks attributed to melting of Gelucire and mannitol were observed at 46.8 and $167.5^{\circ} \mathrm{C}$, respectively (Fig. 3e, f).

DSC curves (Fig. 5a-r) showed the interactions between two carriers (Gelucire and mannitol) and PZQ, which were characterized by changes in profiles of endothermic peaks, peak temperatures, and their corresponding enthalpies (Table 2). For example, the SD 3:1 (PZQ/mannitol) 
Table 4 Effect of SD 3:1 (PZQ/carrier) on the solubility of PZQ $\left(\mu \mathrm{g} \mathrm{mL}^{-1}\right)$ in $\mathrm{HCl}$ solution $0.1 \mathrm{~mol} \mathrm{~L}^{-1}$, water and phosphate buffer solution $0.2 \mathrm{~mol} \mathrm{~L}^{-1}, n=3$

\begin{tabular}{lccc}
\hline Sample & $\begin{array}{l}\text { PZQ solubility in } \\
\text { HCl solution } \\
0.1 \text { mol L }^{-1}\end{array}$ & $\begin{array}{l}\text { PZQ solubility } \\
\text { in water }\end{array}$ & $\begin{array}{r}\text { PZQ solubility in phosphate } \\
\text { buffer solution 0.2 mol L }\end{array}$ \\
\hline PZQ & $164.15 \pm 0.25$ & $225.30 \pm 0.17$ & $206.34 \pm 0.36$ \\
PM 3:1 (PZQ/G) & $14.09 \pm 0.12$ & $371.17 \pm 0.22$ & $240.18 \pm 0.13$ \\
PM 3:1 (PZQ/M) & $11.00 \pm 0.41$ & $346.07 \pm 0.30$ & $115.77 \pm 0.43$ \\
PM 3:1 (PZQ/G + M) & $6.066 \pm 0.18$ & $413.41 \pm 0.11$ & $254.27 \pm 0.25$ \\
SD 3:1 (PZQ/G) & $98.01 \pm 0.22$ & $533.23 \pm 0.18$ & $311.3 \pm 0.28$ \\
SD 3:1 (PZQ/M) & $39.87 \pm 0.25$ & $424.01 \pm 0.27$ & $189.43 \pm 0.12$ \\
SD 3:1 $(\mathrm{PZQ} / \mathrm{G}+\mathrm{M})$ & $63.55 \pm 0.32$ & $518.09 \pm 0.16$ & $471.98 \pm 0.24$ \\
\hline
\end{tabular}

Table 5 Effect of SD 1:1 (PZQ/carrier) on the solubility of PZQ $\left(\mu \mathrm{g} \mathrm{mL}^{-1}\right)$ in $\mathrm{HCl}$ solution $0.1 \mathrm{~mol} \mathrm{~L}^{-1}$, water and phosphate buffer solution $0.2 \mathrm{~mol} \mathrm{~L}^{-1}, n=3$

\begin{tabular}{lccc}
\hline Sample & $\begin{array}{l}\text { PZQ solubility in } \mathrm{HCl} \\
\text { solution } 0.1 \mathrm{~mol} \mathrm{~L}^{-1}\end{array}$ & $\begin{array}{l}\text { PZQ solubility } \\
\text { in water }\end{array}$ & $\begin{array}{l}\text { PZQ solubility in phosphate } \\
\text { buffer solution 0.2 mol L }\end{array}$ \\
\hline PZQ & $164.15 \pm 0.25$ & $225.30 \pm 0.17$ & $206.34 \pm 0.36$ \\
PM 1:1 (PZQ/G) & $14.46 \pm 0.14$ & $342.54 \pm 0.11$ & $301.82 \pm 0.22$ \\
PM 1:1 (PZQ/M) & $12.04 \pm 0.31$ & $382.19 \pm 0.34$ & $157.72 \pm 0.32$ \\
PM 1:1 (PZQ/G + M) & $7.605 \pm 0.15$ & $323.07 \pm 0.20$ & $342.71 \pm 0.28$ \\
SD 1:1 (PZQ/G) & $127.94 \pm 0.24$ & $652.61 \pm 0.18$ & $665.75 \pm 0.19$ \\
SD 1:1 (PZQ/M) & $40.79 \pm 0.18$ & $475.81 \pm 0.23$ & $340.31 \pm 0.31$ \\
SD 1:1 (PZQ/G $+\mathrm{M})$ & $77.86 \pm 0.12$ & $517.78 \pm 0.16$ & $364.17 \pm 0.27$ \\
\hline
\end{tabular}

Table 6 Effect of SD 1:3 (PZQ/carrier) on the solubility of PZQ $\left(\mu \mathrm{g} \mathrm{mL}^{-1}\right)$ in $\mathrm{HCl}$ solution $0.1 \mathrm{~mol} \mathrm{~L}^{-1}$, water and phosphate buffer solution $0.2 \mathrm{~mol} \mathrm{~L}^{-1}, n=3$

\begin{tabular}{|c|c|c|c|}
\hline Sample & $\begin{array}{l}\text { PZQ solubility } \\
\text { in } \mathrm{HCl} \text { solution } \\
0.1 \mathrm{~mol} \mathrm{~L}^{-1}\end{array}$ & $\begin{array}{l}\text { PZQ } \\
\text { solubility in } \\
\text { water }\end{array}$ & $\begin{array}{l}\text { PZQ solubility in } \\
\text { phosphate buffer } \\
\text { solution } 0.2 \mathrm{~mol} \mathrm{~L}^{-1}\end{array}$ \\
\hline PZQ & $164.15 \pm 0.25$ & $225.30 \pm 0.17$ & $206.34 \pm 0.36$ \\
\hline PM 1:3 (PZQ/G) & $7.609 \pm 0.10$ & $407.50 \pm 0.31$ & $382.94 \pm 0.32$ \\
\hline PM 1:3 (PZQ/M) & $3.418 \pm 0.46$ & $280.11 \pm 0.27$ & $222.95 \pm 0.24$ \\
\hline $\mathrm{PM} 1: 3(\mathrm{PZQ} / \mathrm{G}+\mathrm{M})$ & $7.129 \pm 0.28$ & $340.05 \pm 0.10$ & $292.99 \pm 0.18$ \\
\hline SD 1:3 (PZQ/G) & $155.33 \pm 0.16$ & $117.42 \pm 0.14$ & $486.03 \pm 0.31$ \\
\hline SD 1:3 (PZQ/M) & $35.13 \pm 0.15$ & $477.12 \pm 0.45$ & $349.25 \pm 0.14$ \\
\hline SD 1:3 (PZQ/G + M) & $136.10 \pm 0.21$ & $561.34 \pm 0.37$ & $100.94 \pm 0.11$ \\
\hline
\end{tabular}

showed three endothermic peaks at 78.2, 129.4, and $166.3{ }^{\circ} \mathrm{C}$ with an enthalpy of $20.0,9.86$, and $16.4 \mathrm{~J} \mathrm{~g}^{-1}$, respectively. However, the enthalpy should be 73.8 for PZQ and $71.7 \mathrm{~J} \mathrm{~g}^{-1}$ for mannitol (Fig. 5k). On the other hand, PM and SD prepared using mannitol showed any change in the profile of their melting peak.

DSC curves (Fig. 5) of PMs and SDs in ratio 1:1 and 1:3 (PZQ/carrier), respectively, also showed the interaction between carriers and PZQ characterized by some changes mentioned above. The interactions between PZQ and carriers for all tested samples were evidenced due to experimental enthalpy which was different from expected enthalpy. Onset temperature of melting peak of the drug in PM and SD: SD 1:1 (PZQ/Gelucire) showed onset temperature at $103.3{ }^{\circ} \mathrm{C}\left(18.6 \mathrm{~J} \mathrm{~g}^{-1}\right)$ for $\mathrm{PZQ}$, whereas the expected onset should be $140.2^{\circ} \mathrm{C}\left(98.4 \mathrm{~J} \mathrm{~g}^{-1}\right)$ (Table 2).

\section{Infrared Absorption Spectroscopy}

The interaction drug/carrier also was confirmed by absorption spectra of PZQ, Gelucire, mannitol, PMs, and SDs. The SDs (3:1 and 1:1-PZQ/carrier) which showed more extended and intense bands compared with PMs (3:1 and 1:1-PZQ/carrier) at $3300-3450 \mathrm{~cm}^{-1}$ due to a broad band of stretching $\mathrm{O}-\mathrm{H}$, which suggest hydrogen bond of drug/carrier (Fig. 6d-o). 

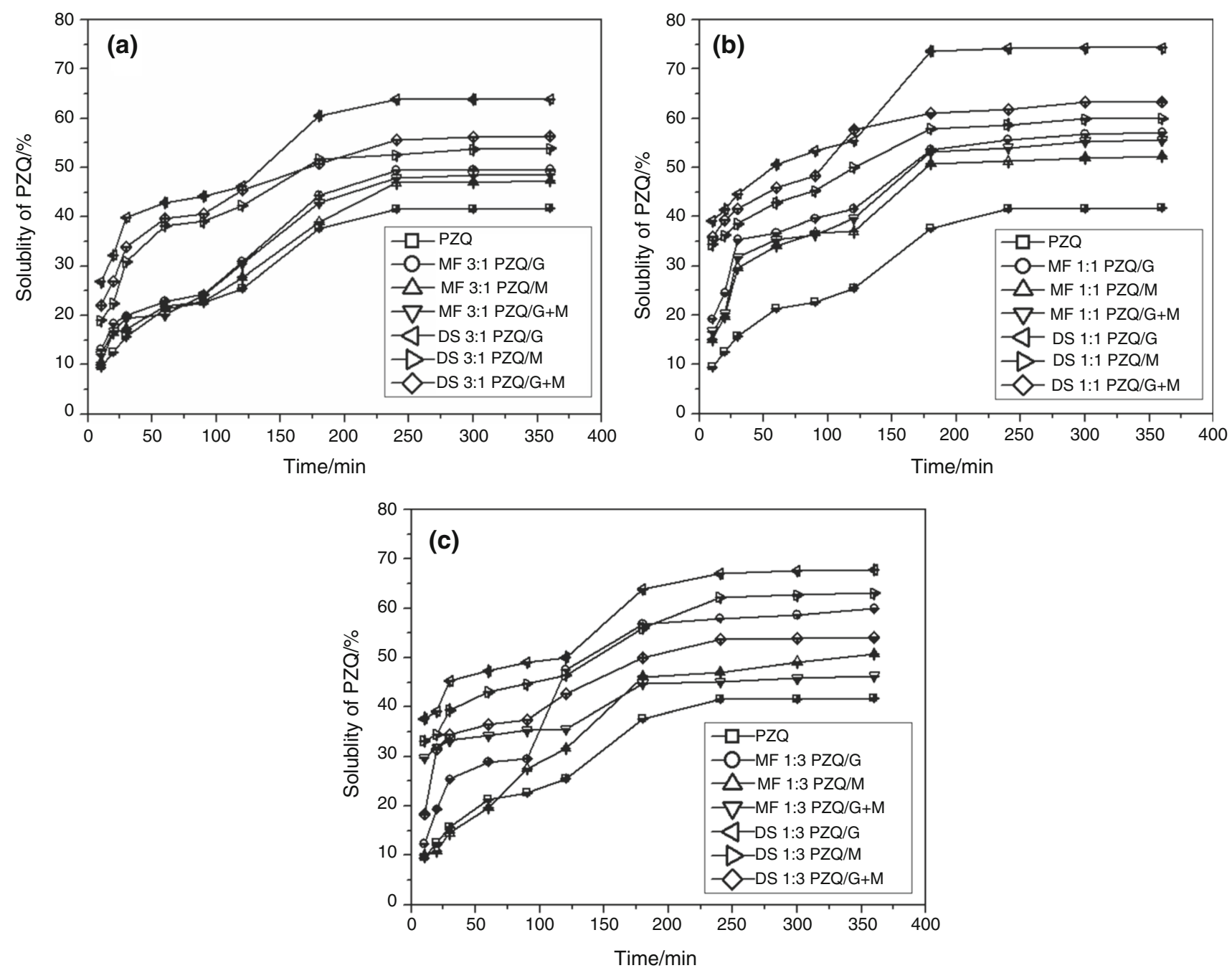

Fig. 9 Dissolution profile a PZQ, PM 3:1 PZQ/carrier and SD 3:1 PZQ/carrier; b PZQ, PM 1:1 PZQ/carrier and SD 1:1 PZQ/carrier; c PZQ, PM 1:3 PZQ/carrier and SD 1:3 PZQ/carrier

This suggestion can be proven because in TG curve was not an observed water mass loss (Fig. 4). However, SD (1:3$\mathrm{PZQ} /$ carrier) showed bands less intense compared with PM (1:3-PZQ/carrier), which suggests smaller interaction than those of other ration (Fig. $6 \mathrm{p}-\mathrm{u}$ ). Infrared spectroscopic data of PZQ, Gelucire, mannitol, PM and SD in proportion 1:1 (PZQ/carrier) are shown in Table 3.

\section{$X$-ray diffraction}

The X-ray diffraction pattern of PZQ (Fig. 7a) showed typical peaks of diffraction $\left(16.4^{\circ}, 19.5^{\circ}, 20.1^{\circ}, 21.2^{\circ}\right.$, $22.5^{\circ}, 24.7^{\circ}, 25.5^{\circ}, 26.9^{\circ}, 36.4^{\circ}, 41.7^{\circ}$ ) [34] similar to diffractogram described by Liu et al. [35].

$\mathrm{X}$-ray patterns with the values of the distances of crystalline planes (d) of PZQ (open circle), Gelucire (open rectangle), mannitol (open diamond), PMs, and SDs in ratio 1:1 (PZQ/carrier), which suggests the level of crystallinity (Fig. 7a-i). Diffractograms of PZQ, mannitol, PMs, and SDs samples showed a crystalline structure with sharp and intense diffraction peaks, whereas the values (d) of PMs were the same presented to PZQ, Gelucire, and mannitol. On the other hand, Gelucire showed some level of crystallinity (peak at $23.3^{\circ}$, which is typical of triglycerides) [19]. The diffraction pattern of SDs was different from values (d) of PMs, suggesting a change in crystalline structure. The same pattern was observed for ratio 1:3 and 3:1 (PZQ/carrier) (Fig. 7j-u). Therefore, the X-ray results showed that the process of preparation of SDs (heating) caused a transformation of PZQ, and the diffractograms of sample of SDs 1:1 PZQ/Gelucire (Fig. 7g) and 1:3 PZQ/ Gelucire (Fig. 7s) demonstrate that there was amorphization of PZQ and appearance of new peaks in the low angle region for all $\mathrm{SD}$. 
Scanning Electron Microscopy (SEM)

The microparticles of Gelucire (Fig. 8b) not presented crystals, while the microparticles of PZQ (Fig. 8a) and mannitol (Fig. 8c) presented crystals. The photomicrographs of PM (Fig. 8d-f, j-l, p-r) presented crystalline structures and can be observed on their surface the presence of PZQ crystals. The photomicrographs of SDs prepared with mannitol (Fig. 8h, n, t) and mannitol + Gelucire (Fig. 8i, o, u) presented aggregation of smaller crystals on the surface of larger particles than PMs. However, in the SDs prepared using only Gelucire (Fig. 8g, m, s) were not observed crystals, it was observed an agglomeration of microparticles similar with Gelucire microparticles.

\section{Solubility assay}

Solubility assay was necessary to evaluate the influence of the quantity of the carrier on the solubility of PZQ. Results are presented as mean \pm SD for $n=3$ (Tables 4-6). PZQ $\left(225.30 \pm 0.17 \mu \mathrm{g} \mathrm{mL}^{-1}\right)$ is very soluble in water at $\mathrm{pH}$ 5.5 , whereas it should be observed a decrease of its solubility in buffered phosphate at $\mathrm{pH} \quad 6.8 \quad(206.34 \pm$ $\left.0.36 \mu \mathrm{g} \mathrm{mL}^{-1}\right)$ and in acid solution (164.15 \pm $0.25 \mu \mathrm{g} \mathrm{mL}^{-1}$ ). To increase the solubility of PZQ, PM and $\mathrm{SD}$ were prepared using mannitol and Gelucire as carriers under two different conditions: in an acid solution to mimic stomach conditions and buffered solution to mimic duodenum conditions. In general, SD in all proportions (PZQ/carrier) submitted to buffered solution showed an increase in the solubility of PZQ. SD prepared using Gelucire and mannitol + Gelucire in ratio 1:3 (PZQ/carrier) provided an increase three and four times higher than pure PZQ, respectively. However, the SD containing PZQ/ Gelucire was considered the greatest due to the solubility of PZQ (717.42 \pm 0.14$)$ in a condition similar to the duodenum (local of large absorption area, $\mathrm{pH}$ 5.5) the (Table 6). On the other hand, in acid solution, all preparations (PMs and SDs) presented a decrease in solubility of PZQ.

\section{In vitro drug dissolution}

This study was carried out to verify the dissolution and release extension of pure PZQ compared with PMs and SDs. The results showed an increase in dissolution and release extension for PMs and SDs. However, SDs presented higher dissolution rate and release extension than PMs. Also, it can be observed that PMs and SDs prepared using Gelucire presented better dissolution profile than PMs and SDs prepared using mannitol (Fig. 9a-c). The PMs and SDs in ratio 3:1 (PZQ/carrier) presented a decrease in dissolution rate compared with PMs and SDs in ratio 1:3 and 1:1 (PZQ/carrier). Similar results observed in SDs are 1:3 and 1:1 (PZQ/carrier); however, the SD 1:1 (PZQ/carrier) was considered the best solution because it was prepared using less carrier compared with SD 1:3 (Fig. 9c).

\section{Conclusions}

This study showed that the dissolution rate and release extension of PZQ could be enhanced greatly by the solid dispersion technique. In the particular case SD obtained by Fusion Method, using Gelucire as a carrier in the ratio 1:1 afforded to increase of PZQ availability approximately twice. Therefore, SD is an important strategy for increasing the solubility and dissolution, a crucial step in the development of a pharmaceutical dosage form containing praziquantel for possible application in the treatment of schistosomiasis.

Acknowledgements Fundação de Amparo à Pesquisa do Estado de São Paulo (FAPESP, Process: 2011/11586-0), Faculdade de Ciências Farmacêuticas de Ribeirão Preto (USP), Faculdade de Ciencias Farmaceuticas de Araraquara (UNESP) and Instituto de Química de Araraquara (UNESP) are gratefully acknowledged for supporting this work.

\section{References}

1. Ghoneim MM, Mabrouk MM, Tawfik A. Direct determination of praziquantel in pharmaceutical formulations and human plasma by cathodic adsorptive stripping differential-pulse voltammetry. J Pharm Biomed. 2002;30:1311-8.

2. Cinto PO, Souza ALR, Lima AC, Chaud MV, Gremião MPD. LC evaluation of intestinal transport of praziquantel. Chromatographia. 2009;69:S213-7.

3. Amidon GL, Lennernãs $H$, Shah VP, Cison JR. A theoretical basis for a biopharmaceutic drug classification: the correlation of in vitro drug product dissolution and in vivo bioavailability. Pharm Res. 1995;12:413-20.

4. Barreto M, Bica A, Farinha A. Sistemas de classificação biofarmacêutica. Bol LEF. 2002;32:2-10.

5. Mainardes RM, Evangelista RC. PLGA nanoparticles containing praziquantel: effect of formulation variables on size distribution. Int J Pharm. 2005;290:137-44.

6. Frizon F, Eloy JO, Donaduzzi CM, Mitsui ML, Marchetti JM. Dissolution rate enhancement of loratadine in polyvinylpyrrolidone K-30 solid dispersions by solvent methods. Powder Technol. 2013;235:532-9.

7. Frezza TF, Gremião MPD, Magalhães EMZ, Magalhães LA, Souza ALR, Allegretti SM. Liposomal-praziquantel: efficacy against Schistosoma mansoni in a preclinical assay. Acta Trop. 2013;1:70-5.

8. Deshmane SV, Biyani KR. Characterization of solid dispersion: a review. Int J Pharm Allied Res. 2014;4:584-9.

9. García-Rodriguez JJ, de la Torre-Iglesias PM, Vegas-Sánchez MC, Torrado-Durán S, Bolás-Fernández F, Torrado-Santiago S. Changed crystallinity of mebendazole solid dispersion: improved anthelmintic activity. Int J Pharm. 2011;403:23-8. 
10. Sethia S, Squillante E. Solid dispersions: revival with greater possibilities and applications in oral drug delivery. Ther Drug Carr Syst. 2003;20:215-47.

11. Chaud MV, Lima AC, Vila MMDC, Paganelli MO, Paula FC, Pedreiro LN, Gremião MPD. Development and evaluation of praziquantel solid dispersions in sodium starch glycolate. Trop J Pharm Res. 2013;12:163-8.

12. Chiou WL, Riegelman S. Pharmaceutical applications of solid dispersion systems. J Pharm Sci. 1971;60:1281-302.

13. Arias MJ, Ginés JM, Moyano JR, Pérez-Martlnez JI, Rabasco AM. Influence of the preparation method of solid dispersions on their dissolution rate: study of triamterene-D-mannitol system. Int J Pharm. 1995; 123:25-31.

14. Dehghan MHG, Saifee M, Hanwate RM. Comparative dissolution study of glipizide by solid dispersion technique. J Pharm Sci Technol. 2010;2:293-7.

15. Sekiguchi K, Obi N. Studies on absorption of eutectic mixtures. I. A comparison of the behavior of eutectic mixtures of sulphathiazole and that of ordinary sulphathiazole in man. Chem Pharm Bull. 1961;9:866-72.

16. Dhirendra K, Lewis S, Udupa N, Atin K. Solid dispersions: a review. Pak J Pharm Sci. 2009;22:234-46.

17. Ford JL, Stewart AF, Dubois JL. The properties of solid dispersions of indomethacin or phenylbutazone in polyethylene glycol. Int J Pharm. 1986;28:11-22.

18. Verheyen S, Blaton N, Kinget R, Van Den Mooter G. Pharmaceutical performance of solid dispersions containing poly(ethylene glycol) 6000 and diazepam or temazepam. J Therm Anal Calorim. 2004;76:405-16.

19. Passerini N, Perissutti B, Moneghini M, Voinovich D, Albertini B, Cavallari C, Rodriguez L. Characterization of carbamazepineGelucire $50 / 13$ microparticles prepared by a spray-congealing process using ultrasounds. J Pharm Sci. 2002;91:699-707.

20. Ginés JM, Veiga MD, Arias MJ, Rabasco AM. Elaboration and thermal study of interactions between cinnarizine and Gelucire ${ }^{\circledR}$ 53/10 physical mixtures and solid dispersions. Int J Pharm. 1995;126:287-91.

21. Martins RM, Siqueira S, Freitas LAP. Spray congealing of pharmaceuticals: study on production of solid dispersions using box-behnken design. Dry Technol Int J. 2012;30:935-45.

22. Patil RM, Maniyar AH, Kale MT, Akarte AM, Baviskar DT. Solid dispersion: strategy to enhance solubility. Int J Pharm Sci Rev Res. 2011;8:66-73.

23. De La Torre P, Torrado S, Torrado S. Preparation, dissolution and characterization of praziquantel solid dispersions. Chem Pharm Bull. 1999;47:1629-33.
24. Oltean EG. Development and validation of a RP-HPLC method for the quantitation studies of praziquantel and pyrantel pamoate. Medicam Vet Vet Drug. 2011;5:64-7.

25. Pontes FLD, Pontarolo R, Campos FR, Gasparetto JC, Cardoso MA, Piantavin MS, Trindade ACLB. Development and validation of an HPLC-MS/MS method for simultaneous determination of ivermectin, febantel, praziquantel, pyrantel pamoate and related compounds in fixed dose combination for veterinary use. Asian $\mathrm{J}$ Pharm Clin Res. 2013;6:191-200.

26. Souza ALR, Andreani T, De Oliveira RN, Kiill CP, Santos FK, Allegretti SM, Chaud MV, Souto EB, Silva AM, Gremião MPD. In vitro evaluation of permeation, toxicity and effect of praziquantel-loaded solid lipid nanoparticles against Schistosoma mansoni as a strategy to improve efficacy of the schistosomiasis treatment. Int J Pharm. 2014;463:31-7.

27. Pharmacopeia US. 30th Rev, US Pharmacopeia Convention, Rickville; 2007. p. 2999.

28. International Conference on Harmonization. Harmonised tripartite guideline, text on validation of analytical procedures, Q2(R1). In: International conference on harmonization of technical requirements for registration of pharmaceuticals for human use; 1996.

29. Mogal SA, Gurjar PN, Yamgar DS, Kamod AC. Solid dispersion technique for improving solubility of some poorly soluble Drugs. Sch Res Libr. 2012;4:1574-86.

30. Chaud MV, Tamascia P, de Lima AC, Paganelli MO, Gremião MPD, de Freitas O. Solid dispersions with hydrogenated castor oil increase solubility, dissolution rate and intestinal absorption of praziquantel. Braz J Pharm Sci. 2010;46:473-81.

31. Dametto PR, Ambrozini B, Caires FJ, Franzini VP, Ionashiro M. Synthesis, characterization and thermal behaviour of solid-state compounds of folates with some bivalent transition metals ions. J Therm Anal Calorim. 2014;115:161-6.

32. Pharmacopeia US. 30th Rev, US Pharmacopeia Convention, Rickville; 2007. p. 387.

33. Pharmacopeia US. 30th Rev, US Pharmacopeia Convention, Rickville; 2007. p. 277.

34. El-Subbagh HI, Al-Badr AA. Praziquantel. Anal Profiles Drugs Subst Excip. 1998;25:463-99.

35. Liu Y, Wang X, Wang JK, Ching CB. Structural characterization and enantioseparation of the chiral compound praziquantel. J Pharm Sci. 2004;93:3039-46. 